\title{
Vegetable Education Program Positively Affects Factors Associated With Vegetable Consumption Among Australian Primary (Elementary) Schoolchildren
}

\author{
Astrid A.M. Poelman, $\mathrm{PhD}^{1}$; Maeva Cochet-Broch, $\mathrm{MSc}^{1}$; David N. Cox, $\mathrm{PhD}^{2}$; \\ Darren Vogrig, $\mathrm{MSc}^{3}$
}

\begin{abstract}
Objective: To measure the effectiveness of a new sensory education program for Australian primary (elementary) schoolchildren (Vegetable Education Resource to Increase Children's Acceptance and Liking [VERTICAL]) designed to increase vegetable enjoyment and positively predispose to vegetable consumption. Methods: Pretest and posttest (collected 2 weeks after intervention) survey data $(\mathrm{n}=299)$ on cognitive, attitudinal, and behavioral factors associated with vegetable consumption were compared between the intervention (which followed VERTICAL, a program consisting of five 1-hour teacher-led interventions) and control students (aged 8-12 years) from Sydney primary schools.

Results: The VERTICAL intervention increased knowledge about vegetables and the senses $(P=.002)$, the ability to verbalize sensations $(P<.001)$, vegetable acceptance $(P=.007)$, and willingness to try vegetables $(P=.05)$. Middle primary students gained more positive attitudes toward vegetable consumption $(P=.009)$. Moreover, VERTICAL had no effect on food neophobia, perceived norms of teacher and peers, emotions, behavioral intentions, and vegetables tried.

Conclusions and Implications: Behavioral change was achieved through VERTICAL in a short intervention, supporting further development and validation.

Key Words: children, elementary schools, primary schools, sensory education, vegetable (J Nutr Educ Behav. 2019;51:492-497.)

Accepted November 1, 2018. Published online December 20, 2018.
\end{abstract}

\section{INTRODUCTION}

Schools provide a good setting to promote healthy eating behaviors in children. A recent meta-review investigating the effect of school-based nutrition interventions on fruit and vegetable intake in primary schoolaged children found an average increase of 0.24 portions of fruit but only 0.07 portions of vegetables. ${ }^{1}$ Thus, there is a need for novel school-based interventions that target vegetable consumption.
Experiential learning strategies are associated with the largest effects in school nutrition education programs. ${ }^{2}$ Recently, sensory education programs were developed. These experiential learning programs focus on the role the senses have in eating, and positively influenced behavioral factors associated with healthy eating, including decreased food neophobia and increased willingness to try new foods, knowledge, ability to describe foods and odors sensorially, intentions to eat healthily, and

\footnotetext{
${ }^{1}$ Commonwealth Scientific and Industrial Research Organisation (CSIRO) Agriculture and Food, North Ryde, New South Wales, Australia

${ }^{2}$ CSIRO Health and Biosecurity, Adelaide, South Australia, Australia

${ }^{3}$ CSIRO Education, North Ryde, New South Wales, Australia

Conflict of Interest Disclosure: The authors' conflict of interest disclosures can be found online with this article on www.jneb.org.

Address for correspondence: Astrid A.M. Poelman, CSIRO Agriculture and Food, 11 Julius Ave, North Ryde, NSW 2113, Australia; E-mail: astrid.poelman@csiro.au

(C) 2018 The Authors. Published by Elsevier Inc. on behalf of Society for Nutrition Education and Behavior. This is an open access article under the CC BY-NC-ND license. (http:// creativecommons.org/licenses/by-nc-nd/4.0/)

https://doi.org/10.1016/j.jneb.2018.11.002
}

perceived subjective norm (from teachers). ${ }^{3-6}$ These programs were not specific to a food category but rather targeted healthy eating behavior in general. They were also relatively extensive (10-18 hours), potentially posing barriers to teachers working with a crowded curriculum. However, a shorter sensory education (5-hour) intervention increased only knowledge and otherwise was ineffective. ${ }^{7,8}$

A novel education program for Australian primary schools was developed with the aim of positively predisposing children to consuming vegetables: Vegetable Education Resource to Increase Children's Acceptance and Liking (VERTICAL). ${ }^{9}$ It is an experiential learning program dedicated to vegetables, combining elements from sensory education and scientific insights into children's development of vegetable acceptance, such as exposure and role modeling. ${ }^{10}$ It is short (five 1-hour interventions) with good curriculum alignment and was positively evaluated by teachers. ${ }^{9}$ 
The current study evaluated VERTICAL's effectiveness in achieving change in students' behaviors toward vegetable consumption.

\section{METHODS}

Baseline measurements were carried out 1-2 weeks before the program was taught. The program was then implemented over 4-5 weeks and posttest data were collected around 2 weeks later. Control schools collected survey data at the same times but continued to follow their regular school curriculum.

\section{Participants}

Participants were students aged 8-12 years in the middle and upper stages of 4 primary schools in Sydney, Australia. Two schools from 2 areas of different socioeconomic disadvantage took part as intervention schools: 1 with a relatively high disadvantage (Socio-Economic Indexes for Areas fourth decile) and 1 with a relatively lower level of disadvantage (Socio-Economic Indexes for Areas seventh decile). ${ }^{11}$ Two control schools were matched by geographic area and hence socioeconomic status. All schools were taking part in the Crunch and Sip program, an ongoing statewide program in which students were encouraged to eat fruits or vegetables supplied by parents or carers during a daily morning break. No schools were involved in other nutrition-related programs at the time of the study. The Commonwealth Scientific and Industrial Research Organisation (CSIRO) Human Research Ethics Committee approved the procedures. Informed consent was obtained from parents.

\section{Measures}

Children self-completed an online questionnaire in class addressing factors relevant to vegetable intake. Questionnaires were completed after instructions and under the supervision of the classroom teacher. The knowledge component and vegetable pictures differed slightly for middle (aged 8-10 years) and upper (aged 10-12 years) students, matching content taught in the unit of work for the particular educational stage. Four qualified primary schoolteachers from participating schools reviewed and approved the questionnaires before data collection for age appropriateness of language, length, and child friendliness. As part of this process, they asked 2-3 students in their class to complete the questionnaire. Appropriate readability was independently confirmed by a readability software program (readable.io, Added Bytes Ltd, Sussex, UK; 2015). The researchers investigated the following factors associated with vegetable intake (Table 1). Knowledge was tested in relation to vegetables and the senses involved in eating, using a combination of true-false statements, multiple choice, and open questions.

Ability to verbalize sensory perceptions was tested by asking students to provide descriptive words for 3 foods. The number of descriptive words (eg, crunchy, sweet) was counted and hedonic words (eg, yucky) were excluded.

Acceptance of 10 common Australian vegetables familiar to most children (carrots, bell peppers, green beans, tomatoes, cauliflower, broccoli, celery, spinach, beets, and peas) ${ }^{12}$ was measured using a 5-point hedonic facial scale.

Table 1. Outcome Variables (Cronbach $\alpha$ ), Number, and Sample Question Format and Answer Categories Measured During Pretest and Posttest Evaluation

\begin{tabular}{|c|c|c|c|}
\hline Determinant & Questions, n & Sample Question & Answer Category \\
\hline Knowledge & 12 & You can eat eggplant raw. & $\begin{array}{l}\text { True/false, multiple choice, open } \\
\text { question }\end{array}$ \\
\hline Verbalization & 3 & $\begin{array}{l}\text { How does this [food/vegetable] } \\
\text { taste and feel in our mouth? } \\
\text { Write as many describing words as } \\
\text { you can. }\end{array}$ & Open question \\
\hline Vegetable acceptance & 10 & How much do you like [vegetable]? & Really dislike (1) to really like (5) \\
\hline Neophobia (0.83) & 13 & $\begin{array}{l}\text { When you see a food for the first } \\
\text { time, you are afraid to taste it. }\end{array}$ & $\begin{array}{l}\text { Strongly disagree (1) to strongly } \\
\text { agree (4) }\end{array}$ \\
\hline Attitude $(0.76)$ & 4 & $\begin{array}{l}\text { It is good to eat a variety of } \\
\text { vegetables. }\end{array}$ & $\begin{array}{l}\text { Yes, definitely (1) to no, definitely } \\
\text { not (5) }\end{array}$ \\
\hline Subjective norm teacher $(0.83)$ & 4 & $\begin{array}{l}\text { My teacher would like me to eat a } \\
\text { variety of vegetables. }\end{array}$ & $\begin{array}{l}\text { Yes, definitely (1) to no, definitely } \\
\text { not (5) }\end{array}$ \\
\hline Subjective norm peers $(0.89)$ & 4 & $\begin{array}{l}\text { My friends would like me to eat a } \\
\text { variety of vegetables. }\end{array}$ & $\begin{array}{l}\text { Yes, definitely (1) to no, definitely } \\
\text { not (5) }\end{array}$ \\
\hline Emotions (0.80) & 8 & I often find vegetables fun. & $\begin{array}{l}\text { Yes, definitely (1) to no, definitely } \\
\text { not (5) }\end{array}$ \\
\hline Intentions (0.87) & 4 & I will eat a variety of vegetables. & $\begin{array}{l}\text { Yes, definitely (1) to no, definitely } \\
\text { not (5) }\end{array}$ \\
\hline Vegetables tried & 4 & Have you ever tried [vegetable]? & Yes /no \\
\hline Vegetables willing to try & 4 & $\begin{array}{l}\text { Would you try [vegetable] if some- } \\
\text { one offered it to you? }\end{array}$ & Yes/no \\
\hline
\end{tabular}


The researchers measured students' own attitudes and perceived attitudes from teachers and peers related to eating and trying a variety of foods and vegetables using a 5-point Likert scale rating 4 statements. Validated scales were used to measure positive and negative emotions ${ }^{13}$ regarding eating new foods and vegetables and behavioral neophobia. ${ }^{14}$

Behavioral intentions for trying and for eating a variety of foods and vegetables were measured using 4 statements formatted according to the behavioral intent scales of the Theory of Planned Behavior. ${ }^{15}$ The researchers measured experience with and willingness to try 4 less commonly consumed vegetables using pictures of vegetables and eliciting dichotomous responses.

Background information collected from each child were sex, age, and school class. Parents provided information about their child's usual vegetable intake (excluding potatoes) in servings per day (representing $75 \mathrm{~g}$ of vegetables) at baseline using a validated scale for adults with adapted response categories, $(0,0.5,1,1.5,2$, $3-4$, and 5 servings). ${ }^{16}$ This question was embedded in the consent form.

\section{Data analysis}

Data were analyzed using SPSS software (version 23.0.0, IBM, Armonk, NY, 2015); $P \leq .05$ was used for statistical significance. Sum scores were calculated for knowledge (range, 0-20), verbalization skills (range, 0-8), willingness to try vegetables (range, 0-4) and vegetables tried (range, 0-4), allo-

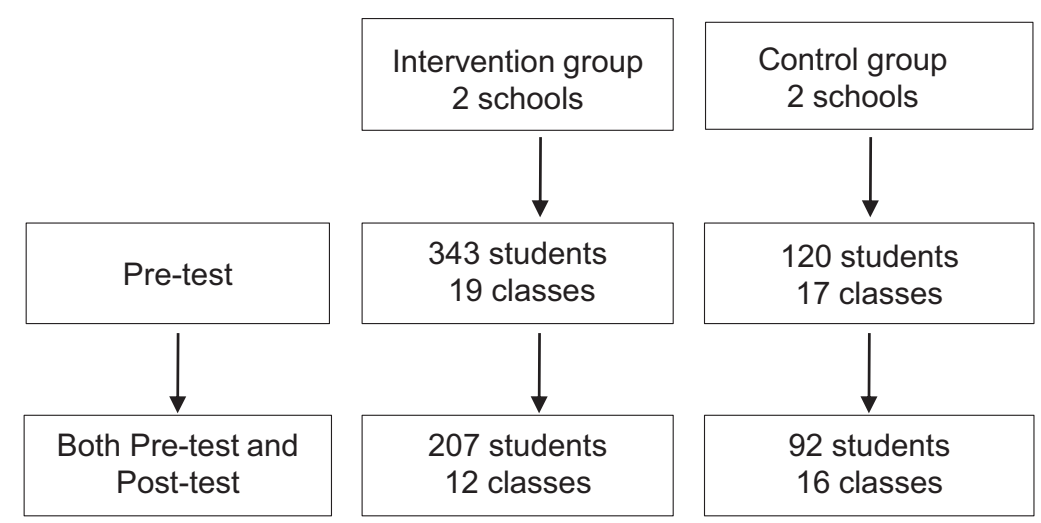

Figure 1. Flow diagram of study participation.

cating 1 point for each correct answer and for each vegetable the child was willing to try or had tried. A mean acceptance rating across all vegetables was calculated. For scales consisting of several items, Cronbach $\alpha$ analysis indicated acceptable (>.7) or good (>.8) internal consistency for all scales, and mean ratings were calculated. Comparison of groups at baseline was undertaken with ANOVA using group (intervention or control) and educational stage as independent factors. To analyze the effect of VERTICAL, repeated-measures ANOVA (and Greenhouse-Geisser correction when sphericity assumption was violated) was conducted on outcome measures with time as the repeated measure and group and educational stage as between-subject factors. Post hoc $t$ tests (using Bonferroni adjustment to correct for multiple comparisons) were undertaken for intervention and control groups separately in case of significant group $\times$ time and/or time effects.

\section{RESULTS}

\section{Characteristics of Participants}

Baseline data were obtained from 463 students (42.0\% of eligible students); 299 students $(27.1 \%$ of eligible students) completed both the baseline and posttest questionnaires (Figure 1). Lower posttest numbers were mostly (74.4\%) the consequence of whole classes not completing the questionnaire owing to other class commitments. Intervention and control group did not differ significantly in sex or vegetable intake (Table 2). Slightly more upper primary students took part in the control than the intervention group (66 vs 52\%), which resulted in a slightly higher age (10.3 vs 9.9 years).

\section{Effect of Vegetable Education}

Students who followed VERTICAL, compared with controls (significant group $\times$ time interaction), differed in

Table 2. Demographic Data for Students in Intervention $(n=207)$ and Control $(n=92)$ Groups

\begin{tabular}{|c|c|c|c|c|c|}
\hline \multirow[b]{2}{*}{ Variable } & \multicolumn{2}{|c|}{ Intervention Group } & \multicolumn{2}{|c|}{ Control Group } & \multirow{2}{*}{$\boldsymbol{P}$} \\
\hline & $\%$ or Mean & SD & $\%$ or Mean & SD & \\
\hline Educational stage $^{a}$ & & & & & $.020^{\star}$ \\
\hline Middle (years 3-4) & 47.8 & & 33.7 & & \\
\hline Upper (years 5-6) & 52.2 & & 66.3 & & \\
\hline Age, $y^{b}$ & 9.9 & 1.1 & 10.3 & 1.3 & $.004^{\star \star}$ \\
\hline Sex ${ }^{a}$ & & & & & .450 \\
\hline Boy & 50.7 & & 45.7 & & \\
\hline Girl & 49.3 & & 54.3 & & \\
\hline Vegetable intake (servings/d) & 1.7 & 1.2 & 1.8 & 1.3 & .630 \\
\hline
\end{tabular}


Table 3. Outcomes Measures and Statistical Significance for Students After the Vegetable Education Intervention $(n=207)$ and for Controls $(n=92)$ during Pretest and Posttest Evaluations

\begin{tabular}{|c|c|c|c|c|c|c|c|}
\hline \multirow[b]{2}{*}{ Outcome Measure } & \multirow[b]{2}{*}{ Group } & \multirow{2}{*}{$\begin{array}{c}\text { Pretest } \\
\text { Mean (SD) }\end{array}$} & \multirow{2}{*}{$\begin{array}{c}\text { Posttest } \\
\text { Mean (SD) }\end{array}$} & \multirow{2}{*}{$\begin{array}{l}\text { Difference } \\
\text { Mean (SD) }\end{array}$} & \multicolumn{3}{|c|}{ Effects $(P)$} \\
\hline & & & & & Group $\times$ Time & Group $\times$ Stage $\times$ Time & Time \\
\hline \multirow[t]{2}{*}{ Knowledge (range, 0-20) } & Intervention & $9.4(4.5)$ & $12.7(5.6)$ & $3.3(4.6)$ & $<.001^{\star \star \star}$ & .15 & $<.001^{\star \star \star}$ \\
\hline & Control & $11.3(4.3)$ & $12.0(4.9)$ & $0.7(4.1)$ & & & \\
\hline \multirow[t]{2}{*}{ Verbalization (range, $0-8$ ) } & Intervention & $3.4(3.1)$ & $4.8(3.4)$ & $1.4(2.7)$ & $.002^{\star \star}$ & .84 & $<.001^{\star \star \star}$ \\
\hline & Control & $4.8(3.5)$ & $5.3(4.0)$ & $0.5(2.7)$ & & & \\
\hline \multirow[t]{2}{*}{ Acceptance (range, 1-5) } & Intervention & $3.4(0.8)$ & $3.6(0.9)$ & $0.2(0.7)$ & .120 & .39 & $.007^{\star *}$ \\
\hline & Control & $3.5(.07)$ & $3.6(0.7)$ & $0.0(0.4)$ & & & \\
\hline \multirow[t]{2}{*}{ Neophobia (range, 1-4) } & Intervention & $2.1(0.5)$ & $2.2(0.6)$ & $0.1(0.5)$ & .810 & .71 & .24 \\
\hline & Control & $2.2(0.6)$ & $2.2(0.6)$ & $0.0(0.5)$ & & & \\
\hline \multirow{2}{*}{ Attitude (range, $1-5)^{a}$} & Intervention & $1.8(0.7)$ & $1.7(0.7)$ & $-0.1(0.7)$ & .080 & $.009^{\star *}$ & .90 \\
\hline & Control & $1.7(0.7)$ & $1.7(0.9)$ & $0.0(0.7)$ & & & \\
\hline \multirow{2}{*}{$\begin{array}{l}\text { Subjective norm teacher } \\
\text { (range, } 1-5)^{a}\end{array}$} & Intervention & $1.9(0.7)$ & $1.9(0.9)$ & $0.0(0.8)$ & 170 & .80 & .42 \\
\hline & Control & $1.8(0.8)$ & $1.9(0.9)$ & $0.1(0.7)$ & & & \\
\hline \multirow{2}{*}{$\begin{array}{l}\text { Subjective norm peers } \\
{\text { (range, } 1-5)^{\mathrm{a}}}\end{array}$} & Intervention & $2.4(1.0)$ & $2.4(1.0)$ & $0.0(1.0)$ & .170 & .60 & .34 \\
\hline & Control & $2.5(1.0)$ & $2.7(1.1)$ & $0.1(0.9)$ & & & \\
\hline \multirow[t]{2}{*}{ Emotions (range, $1-5)^{a}$} & Intervention & $2.3(0.8)$ & $2.3(0.8)$ & $0.0(0.8)$ & .320 & .65 & .68 \\
\hline & Control & $2.2(0.7)$ & $2.2(0.7)$ & $0.0(0.7)$ & & & \\
\hline \multirow{2}{*}{$\begin{array}{l}\text { Intentions to eat } \\
(\text { range, } 1-5)^{a}\end{array}$} & Intervention & $2.1(0.9)$ & $1.9(0.9)$ & $-0.1(0.9)$ & .130 & .26 & .36 \\
\hline & Control & $2.0(0.8)$ & $2.0(0.8)$ & $0.0(0.7)$ & & & \\
\hline \multirow{2}{*}{$\begin{array}{l}\text { Vegetables tried } \\
\text { (range, } 0-4)\end{array}$} & Intervention & $1.4(1.1)$ & $1.4(1.2)$ & $-0.1(1.3)$ & .700 & .84 & .81 \\
\hline & Control & $1.7(1.3)$ & $1.7(1.3)$ & $0.0(0.9)$ & & & \\
\hline \multirow{2}{*}{$\begin{array}{l}\text { Vegetables willing to try } \\
\text { (range, } 0-4 \text { ) }\end{array}$} & Intervention & $1.9(1.3)$ & $2.1(1.4)$ & $0.2(1.4)$ & $.050^{*}$ & .62 & .53 \\
\hline & Control & $2.4(1.4)$ & $2.4(1.4)$ & $-0.1(1.1)$ & & & \\
\hline
\end{tabular}

Note: Repeated-measures ANOVA tests were performed.

${ }^{a}$ Lower scores indicate higher agreement.

${ }^{\star} P \leq .05 ;{ }^{* \star} P \leq .01 ;{ }^{* \star} P \leq .001$.

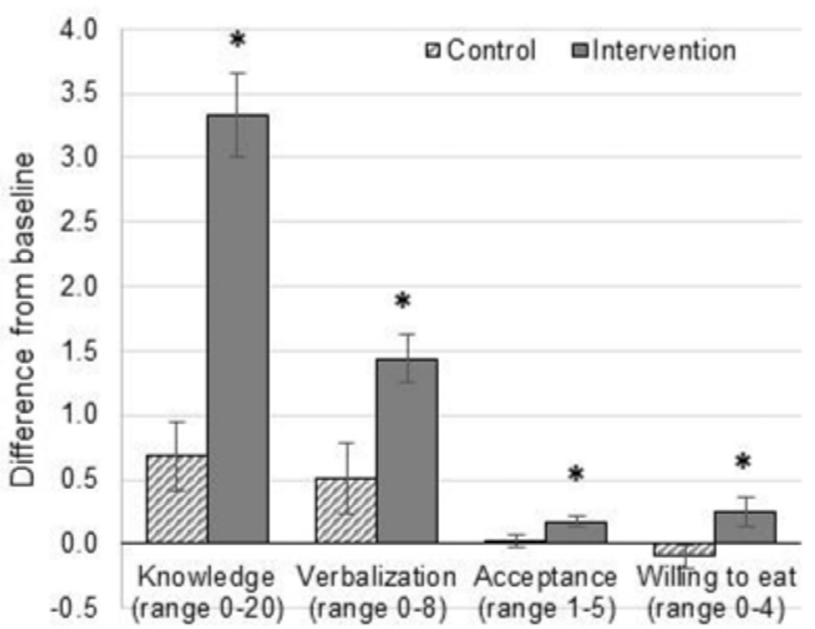

Figure 2. Difference from baseline (as measured by difference between posttest and pretest data) in outcomes (means and SE) from students in control schools (striped gray) and those who took part in the vegetable education intervention (solid gray). ${ }^{\star} P \leq .05$. knowledge $(P<.001)$, verbalization skills $(P=.002)$, and willingness to try vegetables $(P=.05)$ (Table 3$)$. Post hoc testing showed that VERTICAL students significantly increased in their knowledge, verbalization skills, and willingness to try vegetables, whereas control students did not change (Figure 2). An overall increase in vegetable acceptance (significant time effect, $P=.007$ ) was also observed; however, post hoc testing revealed that the intervention group increased in vegetable acceptance whereas the control group did not (Figure 2). In addition, student attitudes showed a significant 3-way interaction among group, time, and educational stage. Further analyses showed that VERTICAL students from middle primary gained more positive attitudes than did control students, whereas this 
effect was not observed in upper primary (data not shown). There was no statistically significant effect of VERTICAL on behavioral neophobia, how students perceived their teacher's or friends' expectations of their behavior, emotions, or specific vegetables tried.

\section{Other Effects}

At baseline, control school students had more knowledge $(P<.001)$ and better verbalization skills $(P=.02)$ than did intervention school students. However, the change in knowledge in the intervention group was larger than the baseline difference (Table 3). The researchers found no other significant differences at baseline.

Various measures showed differences between educational stages. Students from upper primary had more knowledge $(P=.008)$ and verbalization skills $(P<.001)$ than did students from middle primary; they had also tried $(P<.001)$ and were more willing to try vegetables $(P<.001)$. These findings point to general age effects of increased cognitions and experiences that are well reported in the literature.

\section{DISCUSSION}

This study evaluated the effectiveness of a short vegetable education program aimed to predispose students positively to vegetable consumption. The VERTICAL intervention increased knowledge of vegetables and the senses, the ability to verbalize sensations, vegetable acceptance, and the willingness to try vegetables. Middle primary students also gained more positive attitudes toward vegetable consumption.

Effects of VERTICAL were largely similar to those obtained in generic sensory education programs of longer duration (10-18 vs 5 hours) that used similar evaluation tools, including increases in knowledge ${ }^{5}$ and verbalization skills ${ }^{6,17}$ and increased willingness to taste new foods and vegetables. $^{4-6}$ Moreover, a previous intervention of weekly lessons of comparable duration (about 5 hours) found no effect other than increased knowledge. ${ }^{7,8}$ The current authors also found a significant increase in vegetable acceptance, whereas a nonsignificant trend only in acceptance was observed by a much longer sensory education intervention. ${ }^{4}$ The current authors also observed a more positive attitude in the younger age group whereas a longer intervention did not. ${ }^{5}$ These comparisons show that content has a critical role in intervention success and can negate reductions in duration. The difference in the content of VERTICAL, compared with those programs, is that it focused on targeting only vegetables and was based on evidencebased insights about children's development of vegetable acceptance. The relatively short duration of the VERTICAL intervention, which positively influenced behavioral factors toward vegetable consumption, is important for school uptake because of the many competing demands placed on teachers.

There were also some differences from other studies. In contrast to some studies, the current researchers found neither a reduced food neophobia, ${ }^{3,4}$ a generic attitude toward novel foods, nor a subjective norm perceived by teachers. ${ }^{5}$ Together, results seem to indicate that VERTICAL's effect is specific to vegetables and primarily affects student cognitions and attitudes directly.

The positive effects and mechanisms by which acceptance and willingness to try vegetables influence vegetable consumption are broadly known; these include building familiarity with and actually ingesting vegetables when offered. ${ }^{18}$ Intentions are also known strong behavioral predictors. ${ }^{15}$ The mechanisms by which knowledge and ability to verbalize sensations affect behavior are more subtle, including building familiarity to promote acceptance. ${ }^{19}$ The current researchers further hypothesize that they offer the advantage of facilitating normalization processes (ie, the process by which children start to consider vegetables as just another food category in which there are items they can like more or less, rather than adopting a generic negative attitude).

This study had some limitations. There were some differences in baseline measurements between the intervention and control groups. Although schools were matched for geographic area and hence socioeconomic status, there may have been differences in student profiles between schools. School principals adhered strongly to the equality principle; therefore, the use of intervention and control classes within the same school was not possible. The consequences were limited because every student acted as his or her own control, and analyses compared change in the intervention vs control group. There was no random allocation to treatment owing to practical constraints, and intervention schools were recruited first and then matched with comparable control schools. Random allocation could have negated potential bias in the selection process. However, control schools clearly had the same motivation for participating (ie, access to the education materials after the study). Finally, the number of schools in the study was limited. Owing to these factors, this study should be seen as a pilot test and further evaluation of the program among a wider selection of schools representing a broad sociodemographic background is recommended.

\section{IMPLICATIONS FOR RESEARCH AND PRACTICE}

The 2 outcomes in which the strongest effects were found, knowledge and verbalization skills, are both areas in which teachers build significant capability through their education. Vegetable acceptance and willingness to try are domain-specific outcomes and outside current teacher training. Knowledge of food preference development among adults is generally low. ${ }^{20}$ Teacher training on principles of acquisition of vegetable acceptance may enhance the effectiveness of VERTICAL and other nutrition education programs. Further research in this area is recommended.

Classroom-based programs such as VERTICAL are best placed as part of a multicomponent intervention. ${ }^{21}$ The benefit of school-based programs is that all students can benefit regardless of their parents' attitudes, skills, and food choices, and such programs can positively prime children toward 
vegetable consumption. These interventions will complement and strengthen interventions in which actual intake can be changed (eg, school cafeteria and parental interventions).

A short dedicated vegetable education was effective for students aged 8-12 years in increasing knowledge, verbalization skills, acceptance, and willingness to try vegetables. The current results support further development and validation of the VERTICAL program as well as nutrition education programs in other countries targeting vegetable consumption.

\section{ACKNOWLEDGMENTS}

This research was funded by Hort Innovation using the vegetable industry research and development levies with co-investment from CSIRO and contributions from the Australian Government. Hort Innovation is the grower-owned, not-for-profit research and development corporation for Australian horticulture and had no role in the design, analysis, or writing of the article. Nich Archer and Jess Heffernan are thanked for their help with the data collection.

\section{REFERENCES}

1. Evans CE, Christian MS, Cleghorn CL, Greenwood DC, Cade JE. Systematic review and meta-analysis of school-based interventions to improve daily fruit and vegetable intake in children aged 5 to 12 y. Am J Clin Nutr. 2012;96:889-901.

2. Dudley DA, Cotton WG, Peralta LR. Teaching approaches and strategies that promote healthy eating in primary school children: a systematic review and meta-analysis. Int J Behav Nutr Phys Act. 2015;12:28.

3. Reverdy C, Chesnel F, Schlich P, Köster E, Lange C. Effect of sensory education on willingness to taste novel food in children. Appetite. 2008;51:156-165.

4. Mustonen S, Tuorila H. Sensory education decreases food neophobia score and encourages trying unfamiliar foods in 8-12-year-old children. Food Qual Prefer. 2010;21:353-360.

5. Battjes-Fries MC, Haveman-Nies A, Renes R-J, Meester HJ, van 't Veer P. Effect of the Dutch school-based education programme 'Taste Lessons' on behavioural determinants of taste acceptance and healthy eating: a quasiexperimental study. Public Health Nutr. 2014;18:2231-2241.

6. Mustonen S, Rantanen R, Tuorila H. Effect of sensory education on school children's food perception: a 2-year follow-up study. Food Qual Prefer. 2009; 20:230-240.

7. Battjes-Fries MC, Haveman-Nies A, van Dongen EJ, et al. Effectiveness of Taste Lessons with and without additional experiential learning activities on children's psychosocial determinants of vegetables consumption. Appetite. 2016;105:519-526.

8. Battjes-Fries MC, Haveman-Nies A, Zeinstra GG, et al. Effectiveness of Taste Lessons with and without additional experiential learning activities on children's willingness to taste vegetables. Appetite. 2017;109:201-208.

9. Poelman AAM, Cochet-Broch M, Cox DN, Vogrig D. VERTICAL: a sensory education program for Australian primary schools to promote children's vegetable consumption. J Nutr Educ Behav. 2017;49:527-528.

10. Laureati M, Bergamaschi V, Pagliarini E. School-based intervention with children: peer-modeling, reward and repeated exposure reduce food neophobia and increase liking of fruits and vegetables. Appetite. 2014;83:26-32.

11. Australian Bureau of Statistics. Census of Population and Housing: SocioEconomic Indexes for Areas (SEIFA), Australia, 2013. www.abs.gov.au/
AUSSTATS/abs@.nsf/allprimarymainfeatures/8C5F5BB699A0921CCA258259000BA619?opendocument. Accessed June 11, 2018.

12. Poelman AAM, Delahunty CM, de Graaf C. Vegetables and other core food groups: a comparison of key flavour and texture properties. Food Qual Prefer. 2017;56:1-7.

13. Desmet PM, Schifferstein HN. Sources of positive and negative emotions in food experience. Appetite. 2008;50:290-301.

14. Rubio B, Rigal N, Boireau-Ducept N, Mallet P, Meyer T. Measuring willingness to try new foods: a self-report questionnaire for French-speaking children. Appetite. 2008;50:408-414.

15. Fishbein M, Ajzen I. Belief, Attitude, Intention and Behavior: An Introduction to Theory and Research. Reading, WA: Addison-Wesley; 1975.

16. Ball K, Crawford D, Mishra G. Socio-economic inequalities in women's fruit and vegetable intakes: a multilevel study of individual, social and environmental mediators. Public Health Nutr. 2006;9:623-630.

17. Schlich P, Gaignaire A, Reverdy C, et al. Effet d'une éducation sensorielle sur les préférences et les comportements alimentaires d'enfants âgés de 8 à 10 ans. www.eveilogout.com/wp-content/uploads/2014/01/edusens-funfood.pdf. Accessed June 11, 2018.

18. Blissett J, Fogel A. Intrinsic and extrinsic influences on children's acceptance of new foods. Physiol Behav. 2013;121:89-95.

19. Dazeley P, Houston-Price C. Exposure to foods' non-taste sensory properties: a nursery intervention to increase children's willingness to try fruit and vegetables. Appetite. 2015;84:1-6.

20. Carruth BR, Ziegler PJ, Gordon A, Barr SI. Prevalence of picky eaters among infants and toddlers and their caregivers' decisions about offering a new food. J Am Diet Assoc. 2004;104(suppl 1):57-64.

21. Thomson CA, Ravia J. A systematic review of behavioral interventions to promote intake of fruit and vegetables. $J \mathrm{Am}$ Diet Assoc. 2011;111:1523-1535. 
497.e1 Poelman et al

Journal of Nutrition Education and Behavior

(Hort Innovations, Sydney, Australia)

to develop and validate the educa-

The researchers have obtained further funding from the granting body tional research further. 